\title{
Word imagery in recognition memory
}

\author{
SHEILA JONES \\ University College London, London, England \\ and \\ EUGENE WINOGRAD \\ Emory University, Atlanta, Georgia 30322
}

\begin{abstract}
Recognition memory was assessed for words of high- and low-rated imagery after subjects had either spelled them backwards or listened to them in the usual way. The reverse spelling task eliminated the superiority of the high-imagery words in recognition which was shown in the standard condition. While this outcome supports the dual-code hypothesis, the results are complicated by some evidence that low-imagery words are structurally more complex, a factor which may favor their recognition under conditions which require special attention to orthographic features.
\end{abstract}

Recognition memory is known to be better for concrete words than for abstract words (cf. Gorman, 1961; Morris \& Reid, 1974; for a review, see Paivio, in press). One explanation advanced for this phenomenon by Paivio is the dual-code hypothesis which argues that concrete words are more likely than abstract words to be coded in two forms, a verbal representation and a nonverbal or image code. The gain presumably comes about because retrieval of a stored trace is more likely if there is more than one such trace. The dual-code hypothesis has been applied to other findings by Paivio (in press) as well, including higher recall scores associated with concreteness. Recently, in comparing recognition and recall, Paivio (in press) has made the interesting suggestion that recognition may be sensitive to other aspects of words besides their rated imagery (I) value; in particular, he notes that orthographic or surface features of words may play a more important role in recognition than in recall.

In the experiment reported here, a comparison was attempted of recognition memory for high- and low-imagery words which were processed with primary, if not exclusive, attention paid to their orthographic features and with little or, hopefully, no attention paid to other properties such as their potential for evoking nonverbal images. To be specific, subjects were asked to spell high-I and low-I words backwards rapidly and were subsequently given a recognition test. The reader can best appreciate the

This research was supported, in part, by Grant GB-18703 from the National Science Foundation to the second author and was carried out while he was an Honorary Research Fellow of University College London. Reprint requests should be sent to Eugene Winograd, Department of Psychology, Emory University, Atlanta, Georgia 30322. We wish to record our thanks to Tania Yannilos for her assistance in the pilot stage of this experiment. nature of this task by trying to spell "pencil" backwards with the eyes closed (bearing in mind that our subjects heard the words but did not see them) and then trying a low-I word such as "answer." People commonly report that they accomplish this task by visualizing the word, often in parts, and then reading the letters off from right to left. This task suggested itself to us from reading the case study report by Coltheart and Glick (1974) of a female college student with a remarkable talent for "pronouncing in reverse order a word or sequence of words spoken to her; when someone said to her, for example, 'Backwards' she could say, with no delay and perfect fluency, 'Sdrawkcab'. When we asked her how she did it, she said that she could make herself 'see' the spoken word in front of her, and so could read it off easily, in either direction (pp. 438-439)."

Now, if spelling backwards forces one to visualize the physical appearance of the word, which we might call constructing a formal image, then it is highly unlikely that the kind of referential image of a concrete word that is implied in the dual-code hypothesis could be simultaneously generated, as the work of Brooks (1967) and Jones (1972) indicates. It will be assumed here that, in spelling backwards, our subjects were essentially treating all words, whether high or low in rated imagery, in the same fashion as a string of letters. In that case, any difference in recognition memory attributable to more frequent referential imagery for concrete words should disapper. In a nutshell, the dual-code hypothesis should predict no difference in recognition for the high-I and low-I words if these assumptions about the task are valid. On the other hand, if the superior recognition memory associated with high-I words is due, for some reason, to orthographic or surface features, then we should expect the usual superiority to manifest itself even after the words have been spelled backwards. 


\section{METHOD}

\section{Subjects}

The subjects were 24 nonpsychology students of both sexes at University College, London. They were paid for their services.

\section{Materials and Design}

Initially, 60 words of high-rated imagery (mean I value of 6.36 , range of 5.93-6.77) and 60 words of low I (mean $I$ of 3.42, range of 2.13-4.70) were drawn from the norms of Paivio, Yuille, and Madigan (1968). Only words of six or seven letters were chosen. Four lists of 30 words each were then composed from these 120 words with each list containing 15 words each of high and low I. For each subject, two lists were presented during study, with the other two lists providing the distractors on the recognition test. Study and test lists were counterbalanced across subjects. The recognition test sheet was identical for all subjects, consisting of the 120 words from the four lists presented in a random order on a single sheet of paper. On the top of the test sheet, a four-point confidence rating scale was printed for rating the test words as old or new.

A within-subject design was used. During study, each subject was presented with two of the 30-word lists. One list was presented following standard memory instructions with the subject instructed to listen to the words; the other list was presented with the subject told to spell each word aloud backwards. Thus, each subject studied 60 words, half of which were studied in standard fashion and half of which were spelled backwards. In each condition, half of the words were high in rated imagery and half were low.

\section{Procedure}

Subjects were tested individually and told that they would be required to memorize lists of words read to them by the experimenter (S.J.). Before presentation of the list to be spelled backwards, specitic instructions for that task were read, and it was stated that this might be a helpful way to memorize lists of words. Subjects were encouraged to spell the words quickly and were told that they were being timed and that there was a 10 -sec limit. If the subject did not complete spelling the word within $10 \mathrm{sec}$, he was stopped, and the next word was presented. If the subject finished spelling the word before the time limit, the next word was presented inmediately after he had finished. For the standard condition, the subject was told that he would be presented with a list of words at 5-sec intervals and to memorize these in the way he normally would. Immediately after finishing the second study list, an arithmetical task was given lasting $5 \mathrm{~min}$. Following this task, the recognition test was given, and the subject was told to rate each of the 120 test words on the 4-point rating scale. At the conclusion of the experiment, subjects were asked to describe how they had performed the reverse spelling.

\section{RESULTS}

The mean ratings and hit proportions, with ratings of 1 or 2 taken as hits, are shown in Table 1. Analysis of variance of the mean rating scores yields significant outcomes for word imagery $[F(1,23)=5.78, p<.05]$ and for the interaction between type of task and word imagery $[F(1,23)=6.78, p<.05]$. The main effect of task is not significant $[F(1,23)=4.04]$. Since a within-subject design was used, the false alarm proportions cannot be separately determined for the two input conditions. For the high-I distractors, the false alarm proportion was .16 compared with .25 for the low-I distractors. The difference is significant by sign test, $\mathrm{z}=2.86$.

The rating data were also analyzed using Brown's $R$ index (1974), which Brown states is equivalent to the
Table 1

Mean Confidence Ratings and Hit Proportions (in Parentheses)

\begin{tabular}{ccccc}
\hline & \multicolumn{4}{c}{ Condition } \\
\cline { 2 - 5 } Words & \multicolumn{2}{c}{ Standard } & \multicolumn{3}{c}{ Spelling } & Backward \\
\hline High Imagery & 1.48 & $(.84)$ & 1.41 & $(.87)$ \\
Low Imagery & 1.75 & $(.74)$ & 1.47 & $(.86)$ \\
\hline
\end{tabular}

area under the ROC curve. An important difference between the mean rating score used above and the $R$ index is that the latter takes both hits and false alarms into account. The values of $R$ for the standard condition are .87 and .79 for high- and low-I words, respectively; and for the spelling backwards task, .89 and .86 for high- and low-I words, respectively. Analysis of variance for the $R$ index yields significant outcomes for task $[\mathrm{F}(1,23)=4.43, \mathrm{p}<.05]$, word imagery $[F(1,32)=10.29, p<.01]$, and the interaction $[F(1,23)=5.94, p<.05]$.

The important outcome in both analyses is the interaction between word imagery and type of processing. Under the standard presentation condition, recognition memory is superior for the high-I words; when the words have been spelled backwards by the subjects, subsequent recognition of the words seems unaffected by rated imagery.

The amount of time occupied in spelling the words backwards was timed from the tape of the experimental sessions with 21 of the 24 tapes usable. A stopwatch was started as the experimenter said the word and was stopped with the last letter said by the subject (i.e., the first letter of the word). Incomplete attempts were recorded as $10 \mathrm{sec}$, and both incorrect and correct spellings were counted. Incomplete spelling attempts constituted $9 \%$ of the observations, of which 36 were for low-I words and 21 for high-I words. The mean median values were $6.29 \mathrm{sec}$ for the high-I words and $5.86 \mathrm{sec}$ for the low-I words; the difference is significant, $z=2.08, p<.05$. A probable reason for the longer spelling times for the low-I words is their greater structural irregularity. A rough index of this was obtained by making a frequency count of the various consonant-vowel patterns manifested by the six-letter words used. Of 38 six-letter high-I words, 18 conformed to the spelling pattern CVCCVC, whereas only five of 35 low-I words showed this pattern. The modal pattern for low-I words was CVCVCV, as in "malice" and "satire," but only six words make up the modal category. A separate comparison of reverse-spelling times was made for only the six-letter words of two syllables, since there were more low-I words of three syllables. The median reverse spelling times for these words, in which both number of letters and syllables were equated, were $4.99 \mathrm{sec}$ for the high-I words and $5.48 \mathrm{sec}$ for the low-I words, $t(49)=1.78$. Thus, it appears that the additional $1 / 2 \mathrm{sec}$ or so to spell the low-I words backwards is not attributable to length. 
The correlation between the median time taken by subjects to spell backwards and their mean recognition ratings was .36 for the high-I words and .38 for the low-I words. Neither correlation is significantly greater than zero ( $\mathrm{z}$ scores of 1.62 and 1.72, respectively), but the direction of each suggests that faster backward spellers tend to be more confident in recognizing words that they have spelled backwards.

Sixteen of the subjects volunteered that they had visualized the words while spelling backwards; six said that they had repeated the words to themselves. When specifically asked whether they had visualized the words as well, four of these six subjects answered in the affirmative.

\section{DISCUSSION}

Interpretation of the results depends largely on the theoretical assumptions made to account for the better recognition of high-imagery words found under standard study conditions. If one subscribes to a dual-code theory which assumes that two representations, one visual and one verbal, are stored for high-I words as against only a single verbal representation for low-I words, then it is reasonable to argue that spelling backwards eliminates the extra code for the high-I words, thereby producing equivalent recognition for both types of words. But one can follow a similar line of reasoning without any assumptions about imagery by assuming only that it is an essentially semantic feature that differentiates the two types of words. For instance, Richardson (1975) has recently made such an argument for concrete and abstract words in attempting to show that word concreteness $(C)$ and imagery (I) are independent factors. Richardson's point is that concreteness is a lexical feature having little to do with visual imagery. Spelling backwards, it could be argued, does not allow this lexical feature to be encoded for the same reason that it inhibits image formation: the subject is engaged in a difficult type of processing which does not allow these important features to be encoded.

However, a further factor to be taken into account in evaluating any simple interpretation of the results is the possibility that low-I words benefit more than high-I words from the orthographic processing they undergo during reverse spelling. Indeed, the greater structural complexity of the low-I words, as reflected in their more diverse consonant-vowel spelling patterns and longer spelling times, may facilitate their recognition following spelling backwards. Support for this assumption may be found in the work of Zechmeister (1972) showing that orthographic distinctiveness facilitates recognition memory for low-frequency nouns. Different word features no doubt contribute differentially to mnemonic outcomes depending on the specific orienting task used, and the interplay between properties of words and mode of processing may be exceedingly complex.

\section{REFERENCES}

Brooks, L. R. The suppression of visualization by reading. Quarterly Journal of Experimental Psychology, 1967, 19, 289-299.

Brown, J. Recognition assessed by rating and ranking. British Journal of Psychology, 1974, 65, 13-22.

Coltheart, M., \& Glick, M. J. Visual imagery: A case study. Quarterly Journal of Experimental Psychology, 1974, 26, 438-453.

Gorman, A. M. Recognition memory for nouns as a function of abstractness and frequency. Journal of Experimental Psychology, 1961, 61, 23-39.

Jones, S. Imagery in a short-term memory task. Psychonomic Science, 1972, 29, 76-78.

MorRIs, P. E., \& REID, R. L. Imagery and recognition. British Journal of Psychology, 1974, 65, 7-12.

Paivio, A. Imagery in recall and recognition. In J. Brown (Ed.), Recall and recognition. New York: Wiley, in press.

Paivio, A., Yuille, J. C., \& Madigan, S. Concreteness, imagery, and meaningfulness values for 925 nouns. Journal of Experimental Psychology Monograph Supplement, 1968, 76, No. 1, Part 2, 1-25.

Richardson, J. T. E. Concreteness and imageability. Quarterly Journal of Experimental Psychology, 1975, 27, 235-249.

ZeCHMEISTER, E. B. Orthographic distinctiveness as a variable in word recognition. American Journal of Psychology, 1972, 85, 425-430.

(Received for publication August 5, 1975.) 